\title{
A Study to Explore the Relationship between Mindfulness and OCB in IT sector: An Indian Perspective
}

\author{
Yashika Soni ${ }^{1}$, Ramya Dwivedi ${ }^{2 *}$
}

\section{ABSTRACT}

Background: Mindfulness can positively influence organization citizenship behavior, however work-place stress can negatively impact their relationship. Objective: The present study aims at finding the relationship between mindfulness and organization citizenship behavior and also explore the moderating effect of work-place stress on their relationship. Method: The present study surveyed 116 IT sector employees in India. Correlation and regression analysis are used to analyze the data. Results: The results states that there is an insignificant relation between mindfulness and OCB and workplace stress does not have a moderating effect on the relationship between OCB and mindfulness. Conclusion: Mindfulness has no significant impact on OCB which means that weather or not an employee is mindful he/she will indulge in pro-social behavior.

Keywords: Mindfulness, Organization citizenship behavior (OCB), Workplace-stress, Relationship, Organization

This study aims to explore the relationship between awareness about the current scenarios (Mindfulness) and voluntary altruistic behavior in organizational setting (OCB). This research is going to check if there is any impact of the work-place stress on mindfulness and OCB'S relationship. Employees and organizations consistently encounter demands for high performance, an ongoing problem in most workplaces considering that customer satisfaction, sustainable financial growth and success hinge on high performance (Swanson, 1999).

Mindfulness as a psychological construct is the mental training of emotional and attentional regulation that involves the ability to stay focused (Lutz et al., 2008), conscious and present in the moment while being attentive about yourself and others and your surrounding environment (Chaskalson, 2011). Mindfulness simply means being aware about one's present environment, awareness about what's happening at the particular current moment. Mindfulness was first coined by a Buddhist scholar named T.W. Rhys Davids in the early twentieth century. It is derived from a Pali word (an ancient language in India in which

\footnotetext{
${ }^{1}$ Student, MA Psychology, Department of Psychology IILM University, Gurugram, Haryana, India

${ }^{2}$ Associate Professor, PG Psychology, School of Sciences, Jain (Deemed to be University), Bangaluru, Karnataka, India

*Corresponding Author
}

Received: June 26, 2021; Revision Received: September 23, 2021; Accepted: September 30, 2021

(C) 2021, Soni Y. \& Dwivedi R.; licensee IJIP. This is an Open Access Research distributed under the terms of the Creative Commons Attribution License (www.creativecommons.org/licenses/by/2.0), which permits unrestricted use, distribution, and reproduction in any Medium, provided the original work is properly cited. 


\section{A Study to Explore the Relationship between Mindfulness and OCB in IT sector: An Indian Perspective}

teachings of Buddha were originally recorded) "Sati", meaning awareness, attention, and remembering (Siegel et al., 2009).

Mindfulness is also used to characterize organizations that stay "attentive to and aware of what is taking place in their immediate environment"' (Brown and Ryan, 2003: 822). It states that one should be able to introspect about one's internal and external environment which will help in understanding and accepting current scenarios which a person is going through. Mindfulness first entered the corporate world as a luxury relaxation technique and status symbol for those running the show. It is now being disseminated to employees with promises of improved employee overall physical and mental health (i.e., lowered health care costs for employers) and increased productivity (i.e., greater value extracted from employees). (Lobel,2016). Swanson's and Ramiller's article demonstrate the applicability of the mindfulness concept in the IT domain, they mostly concentrate on the institutional bandwagon phenomenon that drives organizations to imitate other organizations in IT innovation and to ignore their own organization and context-specific facts and distinctions. Concerning the cognitive dimension of mindfulness, IT-related problem solving was found to engage organizational actors with diverse skills and preoccupations to share their ideas. (Valorinta,2009). Mindfulness implies a sustained consciousness on the ongoing/current events and experiences in the immediate surroundings instead of being absorbed in the past or anxious about the future (Brown and Ryan, 2003). The science of mindfulness promises to address the worker discontent that these forms of labor engender without confronting the social and economic causes of this discontent (Lobel, 2016).

Organization Citizenship Behavior (OCB) is defined as "individual behavior that is discretionary, which may or may not be accompanied by the formal reward system, and that in the aggregate promotes the effective functioning of the organization" (Organ, 1988). OCB is a kind of voluntary altruistic act performed by the employee apart from the job given to him/her. In general, everyone likes to help one another with no ulterior motive involved, same goes for any formal setting, in every organization if someone is in need the other employee voluntarily helps even if he/she was asked to do it or not it's a social phenomenon. Turnipseed and Rassuli (2005), examples of the particular aspects of OCB that have been identified as bolstering performance include the fostering of social capital, helping behaviors or altruistic actions, elements that result in saving time or problem solving, and other such aspects which have been viewed as providing socio-emotional support through boosting morale or development of a more nurturing culture. Organ $(1988,1997)$ "defined OCB as being voluntary and discretionary behavior of individual organizational members that, in the aggregate, is expected to promote overall organizational effectiveness and efficiency". It is a voluntary behavior so employees are not given any other perks and benefits for performing this pro-social act. OCB enhances organizational efficacy and by increasing production, improving the quality of service provided, promotes client satisfaction or reduction in the customer related complaints (Podsakoff, MacKenzie, Paine, and Bachrach, 2000). OCB has been identified as the second most common form of productive behavior at work (Jex, 1998).

Mart and William (2003) stated that citizenship behaviors must be supervised and properly managed so that such acts can have a positive impact on the behaviors and have enhancing rather than lethal effects on organization and employee overall performance. 


\section{A Study to Explore the Relationship between Mindfulness and OCB in IT sector: An Indian Perspective}

Stress has been defined as the change in one's physical or mental state in response to situations (stressors) that pose challenge or threat (Krantz et al., 1985; Zimbardo et al., 2003). Lazarus (2000) states "stress comes from any situation or circumstance that requires behavioral adjustment. Any type of change, either good or bad, which is affecting the person, is stressful, and whether it's a positive or a negative change, the physiological response happens and is the same. Stress is basically an internal and attached external response to negative stimulus. It impacts the pre-frontal cortex of the brain, that part of the brain which helps in making decisions it has been seen that stress seems to shrinks prefrontal cortex and also cause digestive issues, blood pressure, diabetes, hypertension, headaches, depression, overdoing of substances etc. Stress is not merely a physiological response to a stressful situation. Stress is an interface between that individual and source of demand within their surroundings (Long, 1995).

Work-place stress is caused due to conflict within the organization, or excessive work given, unnecessary deadlines. High demanding jobs can increase the level of stress in the employee. There are many factors that can contribute to work-place stress. These stressors include the employee's appraisal of adaptation to a technologically changing environment, unfavorable management policies, favoritism, and negative organization climate. The changing environment creates misery when that challenge is perceived as a risk to the employee and his or her welfare (Lazarus \& Folkman, 1984).

\section{Relationship of mindfulness, organization citizenship behavior (OCB) and workplace- stress with each other}

Mindfulness is a naturally occurring characteristic which refers to an intrinsic state of awareness in which individuals are attentive to and conscious of present experiences (Brown and Ryan, 2003). Mindfulness refers to processes that keep organizations amenable to their environment, open and inquisitive to new information, and able to effectively contain and handle unpredicted events at the appointed time and in flexible style (Langer and Moldoveanu, 2000a; Levinthal and Rerup, 2006). It helps us understand and embrace our current environment. It helps in understanding our present environment and helps in understanding the information available.

Mindfulness related practices are used today at workplace as a promising and practical approach to manage work-related stress and burnout (Wayne, 2019) and improve overall employee mental health (Van Gordon et al., 2013). OCB is basically pro-social act performed by the employee with or without any rewards attached. This behavior is mostly voluntary and employee indulges in this behavior who seeks to be the part of mix and to satisfy psychological needs. OCBs are a special type of work behaviors that are defined as individual behavior which are advantageous to the organization and are discretionary, even though they are not being rewarded (Sharma et.al 2011). When it comes to examining the performance of employees, OCB is new construct, although the concept was introduced in mid 1980's by Dennis Organ but this concept was never utilized while calculating the rewards because it is voluntary in nature. Examples of OCB include shielding the organization when other employees condemn it and assisting co-workers with their duties. Borman and Motowidlo (1993) suggested that OCB (or 'contextual performance') of workers would serve to improve overall organizational performance. If OCB is high, then we could assume that employee is high on mindfulness because altruistic behavior comes from the fact that a person is aware about himself/herself and their surroundings. Earlier researches have clarified that mindfulness does impact the job performance positively, it 


\section{A Study to Explore the Relationship between Mindfulness and OCB in IT sector: An Indian Perspective}

could be possible that the voluntary behavior that employee is indulging could be due to higher levels of mindfulness. Work-place stress may reflect excessive demands at work place where the individual's incapability to handle a particular situation creates an imbalance between the individual's abilities and demands that can intensify the stress (Jamal 1984; Jamal 1999). While there exist ample researches on mindfulness and its various benefits in the workplace with respect to various dimensions such as job satisfaction, productivity and engagement, there is still lack of clarity in connection between the effect of mindfulness and OCB (Arora, 2021). Nobody can deny the fact that employees are so much under work pressure which may be due to abundance of work or may be due to quarrel amongst the team members or the employee is not getting a chance to utilize their full potential or may be due to lack of camaraderie amongst the employees. There could be many more reason which contributes to stress at workplace, excessive worry could lead to reduction in job-performance and could also affect OCB. Mindfulness will help the employee to reduce work-place stress and might increase OCB which can further reduce the harmful effects of stress. In organizational settings, even brief periods of mindfulness training have been linked with a number of outcomes, including workplace relationships, resilience, task performance, creativity, task commitment, working memory, emotional regulation, high levels of awareness. (Burton, Pakenham, Brown, 2010; Chiesa, Calati, \& Serretti, 2011; Glomb et al., 2012; Jha et al., 2010; Levy, Wobbrock, Kaszniak\& Ostergren, 2012; Sundararajan \&Fatemi, 2016). Overall, mindfulness held constant, older employees in study reported higher rates of citizenship behavior as compared to younger employees. Rationale for this is tough to derive as existing research on the relationship between age and OCB has shown mixed results-some studies showing higher rates for OCB for older employees, and some showing lower rates (Gyekye et al., 2012; Stynen et al., 2015; YungKuei et al., 2015). At the managerial level, citizenship behaviors at the workplace tends to reduce the amount of time a manager has to spend on a given issue, thereby enabling them to focus on other areas for improving organizational effectiveness (Turnipseed \& Rassuli, 2005). Higher job demands cause the employee to perform higher levels of emotional labor, causing emotional fatigue which is negatively related to OCB (Arora, 2021). Jain and Cooper (2012) found a negative relationship between organizational stress and OCB. That is to say stress reduces involvement in the acts of OCB. Social interaction with people has impacted the effect of work-place stressors on organizational citizenship behavior (Pooja Clercq, \& Belausteguigoitia, 2016). When OCB increases, it affects stress directly and indirectly, directly by causing stress to decrease, and indirectly so that respondents who exhibit more OCB experience less work-family conflict, which in turn decreases stress (Tzinera \& Sharonia, 2014). Cameron and Fredrickson (2015) found that two dimensions, current-moment awareness and accepting without judging, not only predicted helping behavior as operationalized by OCB but also predicted increase in positive emotions and decrease in negative emotions associated with those helping behaviors. In one of the previous studies the results suggested that the higher the mindfulness lower will be the level of OCB (Patel, 2017). Study also showed that male employees reported lower levels of OCB as compared to female counterparts (also without considering perceptions of mindfulness) (Patel, 2017). These results could be expected as studies have found that social norms within the workplace often stereotype women helpers without expecting anything in return as compared to men, and those women would like to engage in more types of organizational citizenship behaviors (Beauregard, 2012, Clarke \&Sulsky, 2017; Heilman, 1983). However, Bolino and Turnley (2005) report a positive relationship between OCB and work-place stress. The main benefit of OCB is that it plays a role in overall organizational productivity. Organizational productivity is defined as behavior of the employees working which 


\section{A Study to Explore the Relationship between Mindfulness and OCB in IT sector: An Indian Perspective}

contributes positively to the goals and the objectives of an organization (Campbell, 1990). OCB has now been included in performance evaluation as well (Werner, 1994). Mindfulness offers potential to reduce stress among employees who face challenging work situations. Workers confronting demanding environments cope with those demands by using a variety of resources available to them (Brown \& Ryan, 2003; Schultz, Ryan, Niemiec, Legate, \& Williams, 2015). Organizations are increasingly promoting and imparting training to their employees in the domains of empathy and mindfulness (e.g., Google, Intel, Ford, and General Mills) (Wiesekeet al., 2012; Hafenbrack, 2017). Mindfulness training and interventions help reduce stress (Grossman et al., 2004; Speca et al., 2000) and mindfulness helps people to focus their attention on the here and now moments which has the effect of squeezing attention-competing cognitions and feelings out of consciousness. Emotional individuals do face significant amount of stressful circumstances arising from the workplace. They are able to notice and observe the negative emotions and accept them, rather than acting in a hostile and aggressive or offensive manner because of mindfulness intervention. (Fetterman, Robinson, Ode, \& Gordon, 2010). Motowidlo et al. (1986) report a negative relationship between $\mathrm{OCB}$ and work-place stress. Intelligence has also contributed in improving the performance of OCB (Ajay K Jain, 2012), people with higher level of organizational citizenship behavior will be able to perceive and regulate their own emotions and it also helps in acknowledgement of others emotion when it comes down to helping fellow individuals to develop and they use their emotions effectively for the improvement of the organization. However, Research also indicates that women working in police department generally report higher levels of stress because of negative workplace experiences (Burke \& Mikkelsen, 2005; Hassell \& Brandl, 2009; Morash \& Haarr, 1995). High levels of stress among officers of the law who make sure that the law is followed have collateral effects: job dissatisfaction, absenteeism, premature retirement and attrition (Anderson, Litzenberger \& Plecas, 2002; Ellison, 2004; Ellison \&Genz, 1983; Greene \& delCarmen, 2002). Comparing the workplace experiences of male and female police officer lack of positive organizational climate produces issues at the workplace that can impact its members levels of stress, job satisfaction and organizational commitment (Hassell \& Brandl, 2009; Morash \& Haarr, 1995, Haar \& Morash, 1999). We can say that if there is an increase in the level of job-stress it can affect OCB negatively in general. We know that if the employee is high on stress, it impacts their overall job performance but it can also impact this pro-social behavior because when stress is high a person tend to over think on every matter and its hard for them to concentrate on one thing so it is possible that it impacts OCB negatively.

\section{MATERIAL AND METHODS}

This study is a quantitative research design and for the purpose of this study snowball sampling method was applied to identify the sample group as study participants. They were given an online survey form due to the pandemic. For the purpose of data collection three different scales were administered to the study participants. Correlation and multiple regression analysis are used to analyze the data and explore the relationship between these variables. For doing this work, we have used the software R Studio and excel Scales administered:

1. Mindfulness attention awareness scale: For measuring the aspect of mindfulness, mindfulness attention awareness scale was used which was developed by (Brown \& Ryan, 2003). The MAAS is a 15-item scale, it has statements like I could be experiencing some emotion and not be conscious of it until sometime later, to I snack 


\section{A Study to Explore the Relationship between Mindfulness and OCB in IT sector: An Indian Perspective}

without being aware that I'm eating. It uses 6-point Likert scale ( $1=$ almost always, $6=$ almost never).

2. Organization citizenship behavior scale: $O C B$ was measured using a 10-item scale from Spector Bauer and Fox, 2010. Participants rated the items using a 5-point Likert scale $(1=$ never; $5=$ everyday). It has statements like took time to advice, coach, or mentors a co-worker to give up meal and other breaks to complete work. Higher scores on the scale reflect higher levels of OCB.

3. Workplace stress scale: Workplace stress was assessed using the Work-place stress Scale developed by the Marlin Company, North Haven, CT, USA, and the American Institute of Stress, Yonkers, NY, USA (2001). The work-place stress scale consists of eight items. It is in 5-point Likert scale from (1=never, 5=very often). The items of the scale include, conditions at work are unpleasant or sometimes even unsafe, and I am able to utilize my skills and talents to the fullest extent at work.

Hypothesis 1: There will be a significant relationship between mindfulness and OCB.

Hypothesis 2: Work- place stress will have a moderating effect on the relationship between mindfulness and OCB.

Hypothesis 3: There will be a significant gender difference in the relationship between mindfulness and OCB.

\section{Sample}

IT sector employees were selected as the study participants from few big IT companies working in India. A total of 116 people participated in this study. For the purpose of data collection participants starting as fresher's up till people with 20 years of experience were identified as the sample for this study. The age range of participants was fixed between 22 to 41 years.

\section{RESULT AND DISCUSSION}

We have explored three variables viz mindfulness OCB and work-place stress from the survey responses by averaging the corresponding survey question responses from each participant. This is required to create, for each participant, a consolidated view which has been discussed in the tables.

We had received total 116 responses for this survey. Out of these, 48\%(approx.) of the responses were given by female participants and remaining 52\%(approx.) of responses by male participants. Also, we see that participants with age range of 22 years to 41 years have participated in this survey which means that we have captured the opinion of both who have just started their career in IT and those who have spent significant amount of time in the IT industry. This will also in turn capture sentiment of people who are in a very junior position to people who are leading big teams. This means that the survey data is not significantly skewed towards a certain kind of demographic data i.e. gender and age. Hence, we will be able to capture the relationship more holistically in our analyses.

After plotting the distribution for these variables individually helped in understanding the mean/range of values in the data. We also created scatter plots between OCB \& Mindfulness and Work-place stress \& OCB to understand how these variables behave with respect to each other. On close analysis of these plots, there doesn't seem to be any relationship between OCB and Mindfulness; however, the relationship between Work-place stress and OCB seems to be much stronger. After analyzing the distribution of these variables using 
gender as a central variable, females have higher mindfulness and work-place stress on an average than males while males seem to be high on OCB.

Table 1: Showing percentile distribution of mean/range value of the variables

\begin{tabular}{|l|l|l|l|}
\hline Statistics & Mindfulness & OCB & Work-place stress \\
\hline Mean & 4.104 & 2.891 & 3.071 \\
\hline Median & 4.167 & 2.900 & 3.125 \\
\hline Standard Deviation & 0.863 & 0.578 & 0.397 \\
\hline Minimum & 1.733 & 1.800 & 2.125 \\
\hline Maximum & 6.000 & 4.300 & 3.750 \\
\hline
\end{tabular}

Table 2: Showing percentile distribution of age of participants in the survey

\begin{tabular}{|l|l|l|l|l|l|}
\hline Percentage & $0 \%$ & $25 \%$ & $50 \%$ & $75 \%$ & $100 \%$ \\
\hline age & 22 & 28 & 30 & 34 & 41 \\
\hline
\end{tabular}

Table 3: Showing gender wise distribution in the survey:

\begin{tabular}{|l|l|}
\hline Females & Males \\
\hline 55 & 61 \\
\hline
\end{tabular}

Plots:
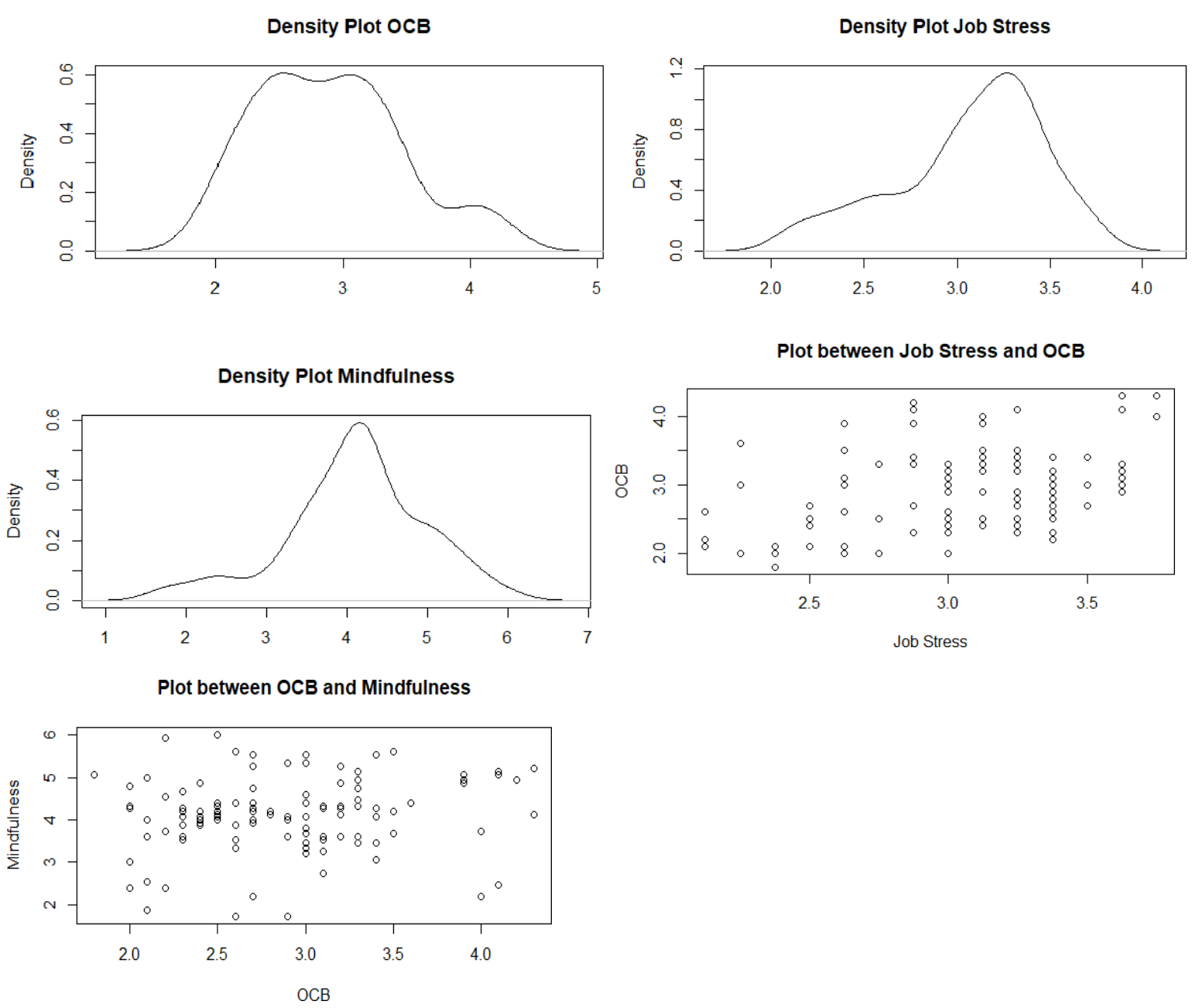

(c) The International Journal of Indian Psychology, ISSN 2348-5396 (e) | ISSN: 2349-3429 (p) | 2352 

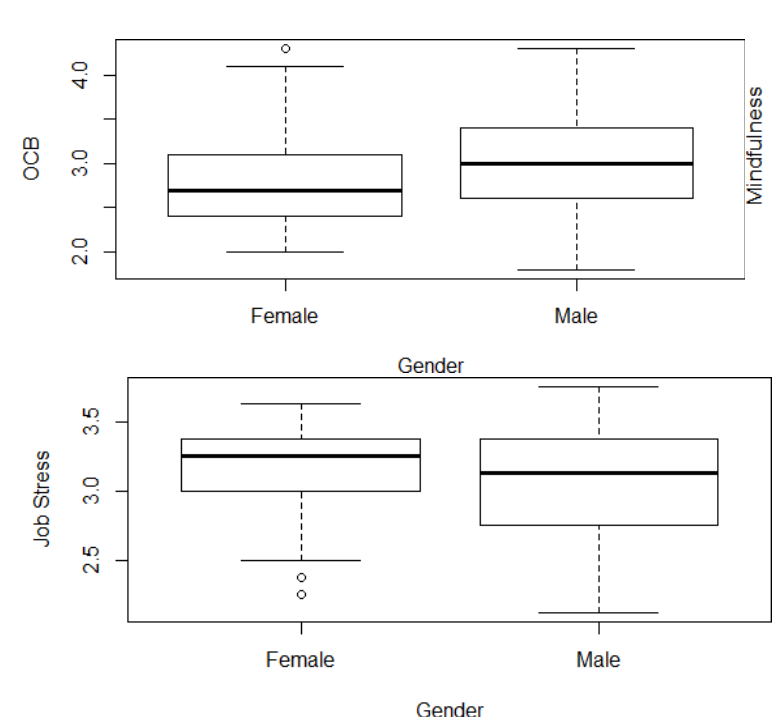

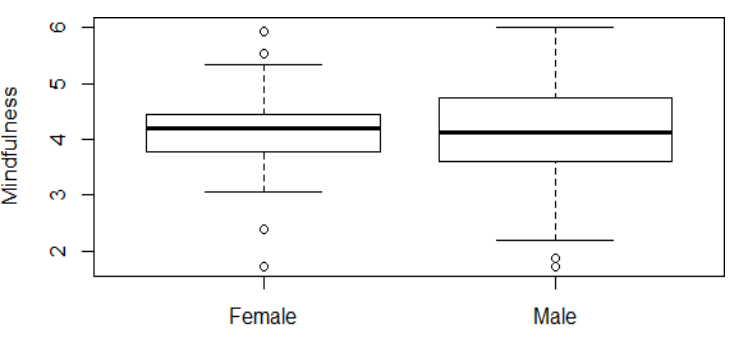

Gender

Two different statistical measures were applied to analyze the data. Pearson correlation was applied to capture linear relationship between OCB and mindfulness, mindfulness and workplace stress and OCB and work-place stress. Multiple Linear Regression analysis was used to fit a line to our data and verify the hypotheses.

As is evident from the correlation table no. 4, Pearson correlation coefficient between mindfulness and OCB (Value: 0.1191975) and Mindfulness and Work-place stress (Value: 0.0900807) is very low and insignificant, however correlation between OCB and work-place stress is significant (Value: 0.3201089) this reveals the finding that both OCB and workplace stress have no significant relation with mindfulness. However, the correlation matrix for males appears more significant than females as shown in table no. $5 \& 6$.

After applying the regression analysis depicted in table no.7 \& 8 following results were found. Work-place stress has statistically significant impact on OCB whereas work-place stress and OCB together have insignificant impact on mindfulness with $\mathrm{p}$ value for both parameters being greater than 0.05. This means that we are unable to reject the null hypothesis postulated in linear regression that the beta coefficient for both variables is 0 .

This result is in line with the correlation results which we have discussed above as well. As shown in table no. $7 \& 8$.

Regression analysis was also used for males and females separately with the hypothesis that gender plays a role in such studies. Upon analyzing those results, the conclusion came was that even though the results are still statistically insignificant separately for both males and females the insignificance level seems stronger for females compared to males. As shown in table no. 9 and 10 .

Table 4: Showing overall correlation matrix between variables

\begin{tabular}{|l|l|l|l|}
\hline Variable & Mindfulness & Work-place-stress & OCB \\
\hline Mindfulness & 1.0000000 & -0.0900807 & 0.1191975 \\
\hline Work-place stress & -0.0900807 & 1.0000000 & 0.3201089 \\
\hline OCB & 0.1191975 & 0.3201089 & 1.0000000 \\
\hline
\end{tabular}


Table 5: Showing correlation matrix between variables (Males)

\begin{tabular}{|l|l|l|l|}
\hline Variable & Mindfulness & Work-place-stress & OCB \\
\hline Mindfulness & 1.0000000 & -0.1514708 & 0.1473544 \\
\hline Work-place stress & -0.1514708 & 1.0000000 & 0.3553180 \\
\hline OCB & 0.1473544 & 0.3553180 & 1.0000000 \\
\hline
\end{tabular}

Table 6: Showing correlation matrix between variables (Females)

\begin{tabular}{|l|l|l|l|}
\hline Variable & Mindfulness & Work-place-stress & OCB \\
\hline Mindfulness & 1.0000000 & -0.009444798 & 0.109638227 \\
\hline Work-place stress & -0.009444798 & 1.0000000 & 0.360460545 \\
\hline OCB & 0.109638227 & 0.360460545 & 1.0000000 \\
\hline
\end{tabular}

Table 7: Showing regression (OCB and Work-place stress) R-squared- 0.1025

\begin{tabular}{|l|l|l|l|l|}
\hline Variable & Coefficient & Std. Error & T Stat & P-Value \\
\hline Intercept & 1.4587 & 0.4001 & 3.646 & 0.000403 \\
\hline Work-place stress & 0.4662 & 0.1292 & 3.608 & 0.000460 \\
\hline
\end{tabular}

Table 8: Showing regression (Mindfulness, OCB and Work-place stress) R-squared0.03253

\begin{tabular}{|l|l|l|l|l|}
\hline Variable & Coefficient & Std. Error & T Stat & P-Value \\
\hline Intercept & 4.3462 & 0.6580 & 6.605 & $1.35 \mathrm{e}-09$ *** \\
\hline OCB & 0.2461 & 0.1458 & 1.689 & 0.094 \\
\hline Work-place stress & -0.3105 & 0.2123 & -1.463 & 0.146 \\
\hline
\end{tabular}

Table 9: Showing regression (Males) R-Squared- 0.06926

\begin{tabular}{|l|l|l|l|l|}
\hline Variable & Coefficient & Std. Error & T Stat & P Value \\
\hline Intercept & 4.5300 & 0.9290 & 4.876 & $8.78 \mathrm{e}-06$ *** \\
\hline OCB & 0.3718 & 0.2188 & 1.699 & 0.0947 \\
\hline Work-place stress & -0.5256 & 0.3053 & -1.721 & 0.0905 \\
\hline
\end{tabular}

Table 10: Showing regression (Females) R-Squared- 0.01478

\begin{tabular}{|l|lll|l|}
\hline Variable & Coefficient & Std. Error & T Stat & P value \\
\hline Intercept & 4.0303 & 0.9323 & 4.323 & $6.98 \mathrm{e}-05 * * *$ \\
\hline OCB & 0.1781 & 0.2023 & 0.880 & 0.383 \\
\hline Work-place stress & -0.1177 & 0.3087 & -0.381 & 0.704 \\
\hline
\end{tabular}

\section{CONCLUSION}

OCB is a voluntary behavior which is shown by an employee to either help a co-worker or help the organization reach their goals without significant selfish motive. In general, we know that mindfulness impacts job performance of an employee in a positive way. Here we have examined if it impacts the pro-social act done by an employee in any significant way or not. This study was done during Covid-19 times and people in all the sectors (not only IT) were trying to save their job due to bad economic situation which resulted in high workplace stress. This resulted in high OCB levels because everyone was trying to save their respective jobs which in some cases also forced people to take up extra responsibilities which ideally should add to altruistic behavior. Extra responsibilities will lead to even more work-place stress because of the additional time that people would have to spend on finishing the office work and pleasing the higher ups. After rigorous statistical analyses on

(C) The International Journal of Indian Psychology, ISSN 2348-5396 (e)| ISSN: 2349-3429 (p) | 2354 


\section{A Study to Explore the Relationship between Mindfulness and OCB in IT sector: An Indian \\ Perspective}

the survey data, it can be concluded that OCB does not have a significant impact on mindfulness and work-place stress does not act as a moderator. In the current study, people seem to have high urge of helping their peers/colleagues or doing extra work for the organization without giving too much attention to rewards and recognition as such. Stress levels are also correlated with OCB as expected however contrary to the general notion that OCB should have positive impact on mindfulness, we see no impact. The potential reason for this result could be that OCB in this case is not completely driven by altruistic tendencies but more by people trying to save their jobs and livelihood which doesn't really add to their mindfulness levels. Also work-place stress is not acting as a mediator for similar reasons as discussed above.

Talking about mindfulness, most of the people are not aware of what mindfulness is or why is it important to be mindful and people would also not be aware about the impact of mindfulness on their overall well-being. They can also work upon it to increase awareness about their immediate environment and awareness about themselves also, some of the techniques that can be practiced could include:

- Practicing guided meditation

- Try to be more observant about oneself and the surroundings

- Maintain a journal, which will remind them that they should appreciate what they possess.

- Exercise daily in the natural environment without the help of any electronic devices.

- Taking some time out for hemselves.

Mindful interventions can enhance positive team culture, social support, group solidity and improve team cooperation and efficiency by endorsing a sense of relationship and candidness among team members and deteriorating restrictions between designation and positions within a group (Johnson et al., 2020). Increasing mindfulness, or even mindful practices, on an individual level can thereby result in a domino effect of psychological and behavioral changes, that could potentially influence workplace behavior, experiences, and have beneficial results for organizations (Patel, 2017). There have been studies wherein results have been similar to this study.

Workplace has a huge impact on overall personality positively, person feels accomplished. It gives a status to him/her in the society and hence it impacts overall well-being of the person. Adding stress to it will create a burn out situation and person will be irritated, frustrated of work, and might be hostile on others because he/she is so worked up. This might eventually hamper the overall job performance also. In this study we see that OCB is positively correlated with work-place stress (for reasons described above) and also it does not show an impact on the relationship between mindfulness and OCB, which in itself is insignificant. This means that stress doesn't act as a moderator as hypothesized. Organizations on one hand need to encourage OCB in their own interest and on the other hand must ensure that the employees are not subjected to work-place stress (Tambe, 2015). Organ (1990) points out that OCB adds to performance and also influences how managers appraise employees.

If we consider gender as a parameter, the results shows that even though the impact of OCB and work- place stress is insignificant for both males and females, relatively the impact on males seem to be higher than females in our study. One of the possible reasons behind this could be that males in Indian society are deemed as primary bread earners hence their main 


\section{A Study to Explore the Relationship between Mindfulness and OCB in IT sector: An Indian \\ Perspective}

focus is excelling at work and making sure that they are able to provide for their family in best possible way. Hence job conditions would impact their mindfulness directly. However, Indian females nowadays are playing multiple roles including the traditional homemaker as well as financially supporting males. This means that their mindfulness can have multiple other drivers than just job conditions. Also given the bad situation during Covid times, their homemaker role would potentially supersede their career which means that relationship between mindfulness' and work-place conditions will be even lower. So, need for mindfulness is there everywhere but OCB depends upon the person. It could also mean that even if stress exists and the person lacks mindfulness he/she would like to indulge in prosocial behavior which is kind of a quality that human beings indulge into no matter what. Work-place stress has been associated with the etiology of physical disorders such as heart disease, hypoadrenia, immune suppression and chronic pain. In addition, the psychological impact of work place stress includes depression, persistent anxiety pessimism and resentment (Colligans \& Higgins, 2005)

Mindfulness research suggests that the state of mindfulness helps people to part environment distinctiveness from their reactions to them, thereby reducing stress (Kabat-Zinn, 1994). Research shows that mindfulness reduces stress for people who are dealing with persistent illness (Grossman, Niemann, Schmidt, \& Walach, 2004; Speca, Carlson, Goodey, \&Angen, 2000). Mindful people tend to ignore irrelevant demands that does not need instantaneous focus that otherwise could contribute to stress. (Grover,et al;2017). Mindfulness interventions and training help people learn that tools of mindfulness have been shown to be highly useful in reducing the stress at workplace along with the other health benefits when being practiced. (Aikens et al., 2014; Hülsheger et al., 2015; Mackenzie et al., 2006; Shapiro, Astin, Bishop, \& Cordova, 2005). Reduction of stress is very important because it impacts the overall well-being of the person. So a few measures that can be taken to reduce stress are as follows. Even if in this study it has not impacted the relationship but in general stress reduction is important.

- Indulge in exercising on the daily basis so as to help channelize negative energy to improve physical health

- Take some time out to do things that you enjoy

- Take a break from the usual routine and start doing something that you have been thinking of doing.

- Practice mindfulness.

- Spend time with family

- Do not ignore the early signs of stress like anger, low energy, insomnia, muscle tension or upset stomach etc.

The results in this study show that there is an insignificant relationship between mindfulness and OCB and work-place stress has no impact on the said relationship. This simply concludes those study participants who were employees in IT firms tends to indulge in prosocial behavior whether or not they are really mindful. Work-place stress has not impacted their said relationship which means that employees going through any amount of stress, would only impact the voluntary altruistic act (or not) performed by them either in favor of the colleague or doing something to help the organization thrive irrespective of whether they are getting rewarded or not but this doesn't directly impact mindfulness. There could be other variables which could definitely impact their relationship in a different manner. Taking gender into consideration, we realized that even though the impact of OCB and work-place 


\section{A Study to Explore the Relationship between Mindfulness and OCB in IT sector: An Indian Perspective}

stress on mindfulness is statistically insignificant for both males and females, males seem to have relatively more impact on mindfulness compared to females. We feel that Covid and dire economic conditions are probably very significant drivers for the results that have been observed in the study.

\section{Implications For Future Research}

This data was collected during covid times; hence people were under significant stress because of extremely bad economic conditions. Also, most of the people would have been under mental stress due to safety concerns for themselves and their family and it's sometimes difficult to differentiate between the two which might have reflected in the responses. Therefore, there is a possibility that the responses to the questionnaires could be a bit biased. Also, IT as a sector is very fast moving in nature which means employees in general have to put in significant effort to be relevant.

1. Survey can be conducted again on the similar demographics after Covid situation is stabilized and then results between two studies should be compared. This can help solidify the reasoning that we have given for our results.

2. The current study is primarily a cross-sectional study because we have captured point in time responses of the participants which may or may not have captured the evolution of mindfulness and OCB. To make this study more comprehensive, in the future we can ask the same participants to fill this questionnaire multiple times over a period of few years (especially key times such as holidays, appraisal time and when employees switch jobs etc.) and then perform longitudinal regression on the resulting dataset.

3. This study can also be done for employees from other sectors to see if sector plays an important role or not e.g., employees in government sector have more job security than private sector but lesser remuneration potential which could give different results.

4. Other parameters such as personality/up-bringing, financial conditions etc. can also be included in the analyses to control for personal factors e.g., person of a better financial stature may take less work-place stress compared to person from poor background while OCB level can still be the same (driven by different reasons).

\section{REFERENCES}

Aikens, K. A., Astin, J., Pelletier, K. R., Levanovich, K., Baase, C. M., Park, Y. Y., \& Bodnar, C. M. (2014). Mindfulness goes to work: Impact of an online workplace intervention. Journal of Occupational and Environmental Medicine, 56, 721-731.

Anderson, G. S., Litzenberger, R., \&Plecas, D. (2002). Physical evidence of police officer stress. Policing: An International Journal of Police Strategies and Management, 25(2), 399-420.

Arora, N. (2021). It's in the Mind-The Relationship between Mindfulness and OCB. Journal of Organizational Behavior: The International Journal of Industrial, Occupational and Organizational Psychology and Behavior, 25(1), 67-80

Beauregard, T. A. (2012). Perfectionism, self-efficacy and OCB: The moderating role of gender. Personnel Review, 41(5), 590-608 Behavioral and Applied Management, pp 86-107.

Bolino, M. C., \&Turnley, W. H. (2005). The personal costs of citizenship behavior: The relationship between individual initiative and role overload, job stress and workfamily conflict. Journal of Applied Psychology, 90. 


\section{A Study to Explore the Relationship between Mindfulness and OCB in IT sector: An Indian \\ Perspective}

Borman, W. C., \&Motowidlo, S. J. (1993). Expanding the criterion domain to include elements of contextual performance. In N. Schmitt, \& W. C. Borman (Eds.), Personnel selection in organizations (pp. 71-98). San Fransisco: Jossey-Bass.

Brinkmann, A. E., Press, S. A., Helmert, E., Hautzinger, M., Khazan, I., \&Vagedes,

Brown, K. W., \& Ryan, R. M. (2003). The benefits of being present: Mindfulness and its role in psychological well-being. Journal of Personality and Social Psychology, 84(4), 822. https://doi.org/10.1037/0022-3514.84.4.822. PMid: 12703651.

Buentello, O., Jung, J., \& Sun, J. (2008). Exploring the casual relationships between organizational citizenship behavior, total quality management \& performance. SWDSI Proceedings, Decision ScienceInstitute.

Burke, R. J., \& Mikkelsen, A. (2005). Gender issues in policing: do they matter? Women inManagement Review, 20(2), 133-143.

Burton, N. W., Pakenham, K. I., \& Brown, W. J. (2010). Feasibility and effectiveness of psychosocial resilience training: a pilot study of the READY program. Psychology, health \& medicine, 15(3), 266-277.

Cameron, C. D., \& Fredrickson, B. L. (2015). Mindfulness facets predict helping behavior and distinct helping-related emotions. Mindfulness, 6(5), 1211-1218.

Campbell, J. P. (1990). Modeling the performance prediction problem in industrial and organizational psychology. In M. D. Dunnette, L. M. Hough (Eds.), Handbook of industrial and organizational psychology, Vol. 1 (2nd ed., pp. 687-732). Palo Alto, CA: Consulting Psychologists Press.

Caring-Lobel, A. (2016). Corporate mindfulness and the pathologization ofworkplace stress. In Handbook of Mindfulness (pp. 195-214). Springer,Cham.

Chaskalson, M. (2011), "The mindful workplace: developing resilient individuals and resonant organizations with MBSR".

Chiesa, A., Calati, R., \&Serretti, A. (2011). Does mindfulness training improve cognitive abilities? A systematic review of neuropsychological findings. Clinical Psychology Review, 31, 449-464.

Clarke, H. M., \&Sulsky, L. M. (2017). The impact of gender ideology on the performance of gender-congruent citizenship behaviors. Human Performance, 30(4), 212-230.

Colligan, T. W., \& Higgins, E. M. (2006). Workplace stress: Etiologyand consequences. Journal of workplace behavioral health, 21(2),89-97.

Colligan, T. W., \& Higgins, E. M. (2006). Workplace stress: Etiology and consequences. Journal of workplace behavioral health, 21(2), 89-97.

Crivelli, D., Fronda, G., Venturella, I., \&Balconi, M. (2019). Stress and neurocognitive efficiency in managerial contexts: A study on technology-mediated mindfulness practice. International Journal of Workplace HealthManagement.

Dunlop, P. D., \& Lee, K. (2004). Workplace deviance, organizationalcitizenship behavior, and business unit performance: The bad apples do spoil thewhole

Ellison, K. W. (2004). Stress and the police officer (2nd ed.). Springfield, IL: Charles C Thomas.

Ellison, K. W., \&Genz, J. L. (1983). Stress and the police officer. Springfield, IL: Charles C.Thomas Publishers.

Fetterman, A. K., Robinson, M. D., Ode, S., \& Gordon, K. H. (2010). Neuroticism as a risk factor for behavioral dysregulation: A mindfulness-mediation perspective. Journal of Social and Clinical Psychology, 29, 301-321. doi:10.1521/jscp.2010.29.3.301

Glomb, T. M, Duffy, M. K, Bono, J. E., \& Yang, T. (2012). Mindfulness at work. Research in Personnel and Human Resource Management, 30, 115-157. 


\section{A Study to Explore the Relationship between Mindfulness and OCB in IT sector: An Indian \\ Perspective}

Goodman, M. J., \&Schorling, J. B. (2012). A mindfulness course decreases burnout and improves well-being among healthcare providers. The International Journal of Psychiatry in Medicine, 43, 119-128

Greene, H. T., \& del Carmen, A. (2002). Female police officers in Texas: perceptions of colleagues and stress. Policing, 25(2), 385-398.

Greensboro NC, Canadian Guidance and Counselling Foundation Ottawa

Grossman, P., Niemann, L., Schmidt, S., \&Walach, H. (2004). Mindfulness-based stress reduction and health benefits: A meta-analysis. Journal Psychosomatic Research, 57, 35-43. doi:10.1016/S0022-3999(03)00573-7

Grover, S. L., Teo, S. T., Pick, D., \& Roche, M. (2017). Mindfulness as apersonal resource to reduce work stress in the job demands-resources model. Stress and Health, 33(4), 426-436

Grover, S. L., Teo, S. T., Pick, D., \& Roche, M. (2017). Mindfulness as a personal resource to reduce work stress in the job demands-resources model. Stress and Health, 33(4), 426-436.

Gu, J., Strauss, C., Bond, R., \& Cavanagh, K. (2015). How do mindfulness-based cognitive therapy and mindfulness-based stress reduction improve mental health and wellbeing? A systematic review and meta-analysis of mediation studies. Clinical Psychology Review, 37, 1-12.

Gyekye, S., Wager, N., \& Malone, C. (2012). The influence of workers' age on organizational citizenship behaviour performances. In A. M. Columbus, A. M. Columbus (Eds.) Advances in Psychology Research (pp. 107-119). Hauppauge, NY, US: Nova Science Publishers.

Haarr, R. N., \&Morash, M. (1999). Gender, race and strategies of coping with occupational stress in policing. JusticeQuarterly, 16(2), 303-335.

Hafenbrack, A.C., 2017. Mindfulness meditation as an on-the-spot workplace intervention. J. Bus. Res. 75, 118-129

Hassell, K. D., \&Brandl, S. G. (2009). An examination of the workplace experiences of police patrol officers: the role of race, sex and sexual orientation. Unpublished manuscript

Hassell, K. D., Archbold, C. A., \&Stichman, A. J. (2011). Comparing the Workplace Experiences of Male and Female Police Officers: Examining Workplace Problems, Stress, Jobc Satisfaction and Consideration of Career Change. International journal of police science \& management, 13(1),37-53.

Heckenberg, R. A., Hale, M. W., Kent, S., \& Wright, B. J. (2020). Trait mindfulness and the Effort-Reward Imbalance workplace stress model: Higher trait mindfulnessis associated with increased salivary immunoglobulin A. Behavioural brain

Heilman, M. E. (1983). Sex bias in work settings: The lack of fit model. Research in Organizational Behavior, 5, 269-298.

Hülsheger, U. R., Alberts, H. J., Feinholdt, A., \& Lang, J. W. (2013). Benefits of mindfulness at work: The role of mindfulness in emotion regulation, emotional exhaustion, and job satisfaction. Journal of Applied Psychology, 98, 310-325.

Hülsheger, U. R., Feinholdt, A., \&Nübold, A. (2015). A low-dose mindfulness intervention and recovery from work: Effects on psychological detachment, sleep quality, and sleep duration. Journal of Occupational and Organizational Psychology, 88, 464489.

Hülsheger, U. R., Lang, J. W. B., Depenbrock, F., Fehrmann, C., Zijlstra, F. R. H., \& Alberts, H. J. E. M. (2014). The power of presence: The role of mindfulness at work for daily levels and change trajectories of psychological detachment and sleep 


\section{A Study to Explore the Relationship between Mindfulness and OCB in IT sector: An Indian Perspective}

quality. Journal of Applied Psychology, 99, 11131120.https://doi.org/10.1037/a0037702.

Jain, A., \& Cooper C., (2012). Stress and organisational citizenship behaviours in Indian business process outsourcing organisations, IIMB Management Review, Volume 24, Issue 3, September 2012, Pages 155-163.

Jain, A.K. (2012), Moderating Effect of Impression Management On the Relationship of Emotional Intelligence and Organizational Citizenship Behavior. Institute of Behavioral and Applied Management, pp 86-107.

Jamal, M. (1999). Job stress and employee well-being: a cross-cultural empirical study. Stress Medicine, 15(3), 153-158.

Jex, S. M. (1998). Stress and job performance: theory, research, and implications for managerial practice-advanced topics in organizational behaviour. Sage Publications Ltd., California; p. 129.

Jha, A. P., Stanley, E. A., Kiyonaga, A., Wong, L., \& Gelfand, L. (2010). Examining the protective effects of mindfulness training on working memory capacity and affective experience. Emotion, 10, 54-64.

Johnson, K. R., Park, S., \& Chaudhuri, S. (2020). Mindfulness training in the workplace: exploring its scope and outcomes. European Journal of Training and Development.

Johnson, K. R., Park, S., \& Chaudhuri, S. (2020). Mindfulness training in the workplace: exploring its scope and outcomes. European Journal of Training and Development.

K. A., Astin, J., Pelletier, K. R., Levanovich, K., Baase, C. M., Park, Y. Y., \& Bodnar, C. M. (2014). Mindfulness goes to work: Impact of an online workplace intervention. Journal of Occupational and Environmental Medicine, 56, 721-731.

Krantz, D., Grunberg , N., and Baum, A. (1985). Health psychology. Annual Review of Psychology, 36, 349-383.

Langer, E. J. and M. Moldoveanu (2000a), 'Mindfulness research and the future,' Journal of Social Issues, 56, 129-139.

Lazarus, J. (2000). Stress Relief \& Relaxation Techniques. Keats Publishing, Los Angeles, CA: NTC/Contemporary Publishing Group, Inc

Lazarus, R. and Folkman, S. (1984). Stress, appraisal, and coping.New York: Springer.

Lee, J. H., Hwang, J., \& Lee, K. S. (2019). Job satisfaction and job-related stress among nurses: The moderating effect of mindfulness. Work, 62(1),87-95.

Levinthal, D. and C. Rerup (2006), 'Bridging mindful and less-mindful perspectives on organizational learning,' Organization Science, 17, 502-513.

Levy, D. M., Wobbrock, J. O., Kaszniak, A. W., \& Ostergren, M. (2012, May). The effects of mindfulness meditation training on multitasking in a high-stress information environment. Paper presented at Graphics Interface Conference, Toronto, Canada.

Long, B. (1995). Stress in the work place: ERIC Digest. ERIC Clearinghouse on Counseling Greensboro NC, Canadian Guidance and Counselling Foundation Ottawa (Ontario). 1995-00-55, ED414521

Lutz, A., Slagter, H.A., Dunne, J.D. and Davidson, R.J. (2008), "Attention regulation and monitoring in meditation", Trends in Cognitive Sciences, Vol. 12 No. 4, pp. 163-169.

Mackenzie, C. S., Poulin, P. A., \& Seidman-Carlson, R. (2006). A brief mindfulness-based stress reduction intervention for nurses and nurse aides. Applied Nursing Research, 19, 105-109 managerial practice. Thousand Oaks, CA: Sage Publications Ltd.

Mart C. Bolino and William H. Turnle. (2003). Going the extra mile: Cultivating and managing employee citizenship behavior. Academy of Management Executive, 201D3. Vol. 17, No 3. 


\section{A Study to Explore the Relationship between Mindfulness and OCB in IT sector: An Indian Perspective}

Morash, M., \&Haarr, R. N. (1995). Gender, workplace problems and stress in policing. Justice Quarterly, 12, 113-140.

Motowidlo, S.P., Packard, J.-S. \& Manning, M. (1986). Occupational stress: Its causes and consequences for job performance. Journal of Applied Psychology, 71.

Mulligan, R. (2018). MINDFULNESS MATTERS: The Effects of Mindfulnesson Organizational CitizenshipBehavior.

Narayanan, K. (2016). The Effect of Emotional Intelligence on Organizational Citizenship Behavior. Asian Journal of Management Research, 7(2),154-169.

Newsome, S., Waldo, M., \&Gruszka, C. (2012). Mindfulness group work: Preventing stress and increasing self-compassion among helping professionals in training. The Journal for Specialists in Group Work, 37, 297-311 13-1128.

Nguyen, T. N. Q., Ngo, L. V., \&Surachartkumtonkun, J. (2019). When do-good meets empathy and mindfulness. Journal of Retailing and Consumer Services, 50, 22- 29

Organ, D. W. (1988). Organizational Citizenship Behavior - The Good Soldier Syndrome: (1st ed.). Lexington, Massachusetts/Toronto: D.C. Heath and Companyhttps://psycnet.apa.org/ record/1988-97376-000.

Organ, D. W. (1997). Organizational citizenship behavior: it's construct clean-up time. Human Performance, 10,85-97.

Organ, D.W., 1990. The motivational basis of organizational citizenship behavior. Research in Organizational Behavior, Greenwich, CT. Organizational Behavior, 5, 269-298.

Patel, T. (2017). Benefits of Mindfulness in the Workplace: The Effects of Mindful Practices on Counterproductive Workplace Behaviors and OrganizationalCitizenship Behaviors.

Podsakoff, P.M., MacKenzie, S.B., Paine, J.B., \& Bachrach, D.G (2000). Organizational citizenship behaviors: A critical review of the theoretical and empirical literature and suggestions for future research. Journal of Management, 26, pp. 513-63.

Pooja, A. A., De Clercq, D., \&Belausteguigoitia, I. (2016). Job stressors and organizational citizenship behavior: The roles of organizational commitment and social interaction. Human Resource Development Quarterly, 27(3), 373-405 a research, 377, 112252

Rioux, S. M., \& Penner, L. A. (2001). The causes of organizationalcitizenship behavior: a motivational analysis. Journal of applied Psychology, 86(6),1306.

Schultz, P. P., Ryan, R. M., Niemiec, C. P., Legate, N., \& Williams, G. C. (2015). Mindfulness, work climate, and psychological need satisfaction in employee wellbeing. Mindfulness, 6, 971-985

Shapiro, S. L., Astin, J. A., Bishop, S. R., \& Cordova, M. (2005). Mindfulness-based stress reduction for health care professionals: results from a randomized trial. International Journal of Stress Management, 12, 164-176.

Sharma, J. P., Bajpai, N., \&Holani, U. (2011). Organizational citizenship behaviorin public and private sector and its impact on job satisfaction: A comparative study in Indian perspective. International Journal of Business and Management, 6(1),67.

Siegel, R.D., Germer, C.K. and Olendzki, A. (2009), "Mindfulness: What is it? Where did it come from?", in Didonna, F. (Ed.), Clinical Handbook of Mindfulness, Springer. New York, NY, pp. 17-35.

Speca, M., Carlson, L. E., Goodey, E., \&Angen, M. J. (2000). A randomized wait-list controlled clinical trial: The effect of a mindfulness-based stress reduction program on mood and symptoms of stress in cancer outpatients. Psychosomatic Medicine, 62, 613-622. 


\section{A Study to Explore the Relationship between Mindfulness and OCB in IT sector: An Indian \\ Perspective}

Spector, P. E., Bauer, J. A., \& Fox, S. (2010). Measurement artifacts in the assessment of counterproductive work behavior and organizationalcitizenship behavior: Do we know what we think we know?.Journal of Applied Psychology, 95(4),781.

Stynen, D., Forrier, A., Sels, L., \& De Witte, H. (2015). The relationship between qualitative job insecurity and OCB: Differences across age groups. Economic \& Industrial Democracy, 36(3), 383-405.

Sundararajan, L., \&Fatemi, S. M. (2016). Creativity and symmetry restoration: Toward a cognitive account of mindfulness. Journal of Theoretical and Philosophical Psychology, 36(3), 131.

Swanson, E. B. and N. C. Ramiller (2004), 'Innovating mindfully with information technology,' MIS Quarterly, 28, 553-583.

Tambe, S. (2015). A study of organizational citizenship behaviour and job stress ina manufacturing company inMumbai.

Turnipseed, D. (1996). Organization citizenship behaviour: an examination ofthe influence of the workplace. Leadership \& Organization DevelopmentJournal.

Turnipseed, D.L., \&Rassuli, A., (2005). Performance perceptions of organizational citizenship behaviors at work: A bi-level study among managers and employees. British Journal ofManagement, 16, 231-244.

Tziner, A., Sharoni, G., (2014). Organizational citizenship behavior, organizational justice, job stress, and work-family conflict: Examination of their interrelationships with respondents from a non-Western culture. Journal of Work and Organizational Psychology 30 (2014) 35-42 - Vol. 30.

Valorinta, M. (2009). Information technology and mindfulness in organizations. Industrial and Corporate Change, 18(5), 963-997.

Valorinta, M. (2009). Information technology and mindfulnessinorganizations. Industrial and Corporate Change, 18(5),963-997

Van Gordon, W., Shonin, E., Sumich, A., Sundin, E. and Griffiths, M.D. (2013), "Meditation awareness training (MAT) for psychological wellbeing in a sub-clinical sample of university students: a controlled pilot study", Mindfulness, Vol. 5, pp. 381391, doi: 10.1007/s12671-012-0191-5.

Van Gordon, W., Shonin, E., Zangeneh, M., \& Griffiths, M. (2014). Work-related mental health and job performance: Can mindfulness help? International Journal of Mental Health and Addiction, 12, 129-137.

Werner, J.M., 1994. Dimensions that make a difference: Examining the impact of in-role and extra-role behaviors on supervisory ratings. Journal of Applied Psychology, 79, 98-107.

Wieseke, J., Geigenmuller, A., Kraus, F., 2012. On the role of empathy in customeremployee interactions. J. Serv. Res. 15 (3), 316-331.

Witschel, N. K. M. (2019). The relationship between mindfulness and specific workplace outcomes (Master's thesis, Faculty ofCommerce).

Wongtongkam, N., Krivokapic-Skoko, B., Duncan, R., \&Bellio, M. (2017). The influence of a mindfulness-based intervention on job satisfaction and work-related stress and anxiety. International Journal of Mental Health Promotion, 19(3),134-143.

Yang, J., Tang, S., \& Zhou, W. (2018). Effect of mindfulness-based stress reduction therapy on work stress and mental health of psychiatric nurses. PsychiatriaDanubina, 30(2), 189-196.

Yung-Kuei, H., McDowell, J., \& Vargas, P. (2015). How old I feel matters: Examining agerelated differences in motives and organizational citizenship behavior. Journal of Park \& Recreation Administration, 33(1), 20-39. 


\section{A Study to Explore the Relationship between Mindfulness and OCB in IT sector: An Indian Perspective}

Želvys, R., Zabardast, A., Nemati, S., Adak, K., \& Shariati, O. (2019). Mindful principals in effective schools: mediating role of organizational climate and organizational citizenship behavior. Pedagogika, 2019, t. 133, nr. 1, p.5-27.

Zimbardo, P., Weber, A., and Johnson, R. (2003). Psychology: Core concepts (4th ed.). Boston: Allyn \& Bacon.

\section{Acknowledgement}

I would like to thank my guide Dr. Ramya Dwivedi for her constant guidance and immense support without which this study wouldn't have been possible. I would also like to thank Mr. Rishabh Soni for his timely guidance and statistical help that he did during this research study.

\section{Conflict of Interest}

The author(s) declared no conflict of interest.

How to cite this article: Soni Y. \& Dwivedi R. (2021). A Study to Explore the Relationship between Mindfulness and OCB in IT sector: An Indian Perspective. International Journal of Indian Psychology, 9(3), 2346-2363. DIP:18.01.224.20210903, DOI:10.25215/0903.224 